\title{
Identidade e sujeito: os coletivos do nordeste discutindo as diferenças
}

\author{
Identity and subject: northeast collectives \\ discussing diferences
}

Identidad y sujeto: colectivos noreste que discutiran diferencias

Recebido em 29-08-2020

Modificado em 21-11-2020

Aceito para publicação em 19-12-2020

doi)https://doi.org/10.47456/simbitica.v8i2.36381

\section{Iara Cavalcante Melo}

ORCID: 0000-0001-8819-760X

Doutoranda em Sociologia, Universidade Federal de Pernambuco, Recife, Brasil; Mestre em Sociologia pela Universidade Federal do Piauí, Teresina, Brasil. A pesquisa teve o apoio da FAPEPI/CAPES; Integrante do Grupo de Pesquisa Redes, Sociabilidades e Poder (PPGS/UFPE). E-mail: iara.cmelo@ufpe.br

\section{Resumo}

Este artigo tem como objeto os coletivos, organizações que têm sido apontadas na literatura como uma mobilização "nova" de pessoas que se formam na sociedade brasileira. Por meio dos estudos já produzidos, são atribuídas algumas características e dentre elas estão: a fluidez, a fragmentação e a heterogeneidade. $O$ trabalho objetiva contribuir para uma compreensão dos coletivos não voltada exclusivamente para a sua análise "organizacional", mas adentrar mais especificamente no campo das identidades que formam essas organizações através dos seus sujeitos e respectivos propósitos. Os dados analisados provêm de pesquisa empírica realizada junto a seis coletivos de estados da Região Nordeste, os quais apresentam diferentes marcadores sociais da diferença em suas construções.

Palavras-chave: coletivos; modernidade; pós-modernidade; identidades. 


\section{Introdução}

A contemporaneidade tem proporcionado a emergência de diferentes tipos de organizações e formas de ativismos. Os coletivos apresentam-se como um dos resultados dessa dinâmica das relações sociais. Eles têm ganhado grande visibilidade na última década, por conta de sua fácil formação, e presença em quase todo o país. Embora o termo "coletivo" não seja uma novidade (Perez, 2020), tem se tornado recorrente nos recentes estudos sobre movimentos sociais, mas remetendo comumente a organização de agrupamentos que se distanciam das experiências mais formalizadas de organizações de movimento sociais, quer seja sobre a dimensão organizacional, quer seja sobre formas de atuação política.

Mesmo apresentando-se como agrupamentos em ascensão, ainda se tem uma produção reduzida sobre os coletivos, o que dificulta a construção de um conceito - a sua fluidez poderia ser uma das dificuldades - ou uma análise aprofundada a respeito desse objeto. $\mathrm{Na}$ prática, no Brasil, os coletivos, na sua grande maioria, se formam nas universidades e por meio digital - facebook, whatsapp, instagram, twitter -, discutindo temas relacionados a marcadores sociais da diferença, de gênero, de raça, educação, sexualidade, classe, arte, urbanismo etc. (Gohn, 2017; Perez; Souza, 2017).

Em um levantamento realizado por Perez e Filho (2017) foram identificados somente 12 artigos que tratam de coletivos publicados em plataformas acadêmicas como Scielo e periódicos da CAPES, demonstrando pouca produção sobre esse novo tipo de organização. No contexto brasileiro, até aquele ano havia sete artigos em que os coletivos eram objetos de estudos $^{1}$, e tais produções apenas os analisam como estudos de casos.

A partir de 2017, observa-se o crescimento latente de estudos e pesquisas sobre coletivos no Brasil em periódicos e congressos, como, aparentemente, uma resposta à expansão e proliferação desses grupos por todo o país, o que talvez tenha feito os analistas crerem que os coletivos não são formas de agrupamentos passageiros. Essas produções trazem análises empíricas com diferentes enfoques teóricos-analíticos. Nos estudos já produzidos, os coletivos foram analisados por diferentes perspectivas, relacionando com os movimentos da juventude (Maia, 2013; Borelli; Abobobeira, 2011; Gohn, 2017; Silva; Campos, 2019; Penteado; Oliveira, 2019); intercalados com as teorias dos movimentos sociais, aproximandoos a uma nova vertente intitulada de "novíssimos movimentos sociais" (Augusto; Rosa;

\footnotetext{
${ }^{1}$ Quais sejam, Mesquita (2008), Borelli eAboboreira (2011), Siqueira e Lago, (2012), Costa e Paulon (2012), Maia (2013), Ferreira (2015), Amador e Castro (2016). Cinco são de pesquisadores estrangeiros, um da Venezuela, Saprieza (2015); outro do Chile, Mora e Rios (2009), Índia, Desouza (2012) e dois dos Estados Unidos, Bordt (1990) e Valk (2002).
} 
Resende, 2016; Gohn, 2017; Perez; Souza, 2017; Melo; Perez,2018) ou como agrupamentos juvenis que se formam devido a crises representativas com relação a formas tradicionais de representação/atuação (Mesquita, 2008; Maia, 2013; Lima; Schmitz, 2017; Lima, 2018; Perez, 2018); ou como um fenômeno que busca confrontar estruturas morais tradicionais através da criação de novos espaços de integração (Costa; Paulon, 2012; Siqueira; Lago, 2012; Melo; Perez, 2018; Assis, 2018) e, neste contexto, podendo ou não se articular com o Estado ou formas tradicionais de fazer política (Borelli, Aboboreira, 2011; Peralva, 2017; Marques; Marx, 2020).

Em meio a todas essas análises de casos, poucas são voltadas para coletivos que atuam na região Nordeste ${ }^{2}$ do Brasil. O Nordeste, historicamente, enfrenta dificuldades em ascender econômica e socialmente, mesmo com uma grande diversidade natural, cultural, identitária, econômica e vasto território. Por meio desse recorte geográfico, nos é permitido compreender as questões que refletem nos atores que ali habitam e que por meio de novas formas de organização social podem ter reinventado meios de emancipação social, a partir de suas experiências particulares que não se entrelaçam com centros hegemônicos de produção de ações coletivas do país (Avritzer, 2007; Araujo, 2018).

A diversidade de pautas que compõe e forma os coletivos demonstra a multiplicidade presente na sociedade contemporânea, e a importância de compreender as identidades dos sujeitos que são atravessados por clivagens sociais e que se juntam apesar das diferenças no que tange as demandas e objetivos a variarem conforme os marcadores sociais da diferença. Entender quais são os marcadores sociais da diferença que guiam a formação dos coletivos na região nordeste do Brasil proporciona uma visão sociológica sobre o panorama social em que os sujeitos dessa região estão inseridos. Questiona-se de que forma é possível compreender os sujeitos, os marcadores sociais que os atravessam e os seus objetivos ao se organizarem por meio de um coletivo.

Para conseguirmos essa análise, utilizaremos dados que provêm de uma pesquisa empírica realizada em três etapas: 1) inicialmente foi feita uma pesquisa exploratória no segundo semestre de 2018, na internet, para encontrar agrupamentos que tinham como foco principal de pauta questões de classe ${ }^{3}$, atuantes no Nordeste. Foram encontrados 26 (vinte e

\footnotetext{
${ }^{2}$ De acordo com censo feito pelo IBGE (Instituto Brasileiro de Geografia e Estatística) no ano de 2010, o Brasil possuía 190.755.799 habitantes, dos quais 53.081.950 são nordestinos, o que faz da região nordeste a segunda região mais populosa do país, composta por nove estados da federação, perdendo só para a região sudestes em termos populacionais (IBGE, 2010).

${ }^{3}$ A escolha desse marcador específico veio da necessidade de analisar a presença ou não de características que confrontassem afirmações de estudos anteriores que apontam elementos como apartidarismo e anarquismos
} 
seis) coletivos, dos quais selecionamos 08 (oito) para a pesquisa, que se mostraram acessíveis e interessados em participar da mesma; 2) dos 08 (oito) coletivos, trabalhamos com 06 (seis) grupos que se apresentavam como coletivos classistas nas descrições de suas páginas na internet, e possuíam também em sua formação, outros marcadores sociais da diferença, além de se organizarem em campos universitários ${ }^{4}$. O contato foi iniciado através da técnica de snowball $^{5}$ (Bola de Neve); 3) Com a aplicação da técnica snowball os 06 (seis) coletivos indicaram apenas 1 (um) agrupamento cada. A partir das indicações chegamos a 11 (onze) coletivos presentes nos estados do Maranhão, Piauí, Ceará, Pernambuco, Rio Grande do Norte, Paraíba, Alagoas e Bahia. No estado de Sergipe não foi encontrado coletivo na rede social Facebook e nem teve indicação dos outros coletivos.

Do total de 17 (dezessete) coletivos, onde 06 (seis) vieram do estudo exploratório e 11 (onze) da técnica de snowball, 07 (sete) foram efetivamente entrevistados nos estados do Maranhão (01), Piauí (02), Pernambuco (01), Alagoas (01), Rio Grande do Norte (01) e Bahia (01). Para garantir o anonimato dos sujeitos que contribuíram com a pesquisa, foram identificados com o nome do estado a que pertence cada coletivo, a exemplo de "coletivo Pernambuco".

Localizados os coletivos, foram realizadas entrevistas semiestruturadas. O roteiro contou com questões sobre definição de coletivo, criação, organização, ações, demandas, relação com o Estado e outras instituições. As questões abordadas neste artigo tratarão de 05 perguntas que irão nos ajudar a compreender as identidades que constituem esses coletivos: 1) O que eles entendem por coletivo? 2) Por que decidiram se organizar em coletivos e não em outro tipo de organização? 3) Qual o objetivo (a finalidade) do coletivo? 4) Existe um perfil dos participantes que compõe o grupo? 5) A falta ou a pouca discussão abordando as temáticas de raça, gênero, classe, política influenciaram a criação do agrupamento?

As entrevistas semiestruturadas foram realizadas com um integrante de cada coletivo, maior de 18 anos, sendo qualquer integrante do grupo apto a responder as questões, independente de sexo e orientação política - visto que os coletivos se apresentam na literatura como organizações horizontais, sem hierarquia (líder dirigente). Mas, no coletivo da Bahia, constituído só por mulheres, todas as integrantes participaram da entrevista.

nesses agrupamentos. Esse recorte não inviabilizou a análise de outras perspectivas sobre esses coletivos, por serem grupos que apresentam múltiplas pautas, outros marcadores foram apresentados por eles.

${ }^{4}$ A universidade é um local que facilita a reunião e organização desses grupos (Perez, 2018), mas isso não significa que eles tenham relação institucional com essas instituições.

5 Essa técnica é uma amostra não probabilística, em que são localizados participantes iniciais e esses indicam novos participantes até que se atinja o "ponto de saturação", ou seja, os mesmos sujeitos começam a ser indicados (Biernacki; Waldorf, 1981). A técnica é recomendável para rastrear grupos, pois os sujeitos entrevistados não são definidos a priori, mas sim empiricamente pela indicação dos seus colegas. 
Este artigo está estruturado em dois blocos: apresentação de um breve debate sobre as diferentes formas de questões da identidade, utilizando os prismas analíticos da modernidade e pós-modernidade, relacionando-as com discussões atuais sobre heterogeneidades e as diferentes percepções do sujeito; e discussão dos dados da pesquisa em conjunto com a literatura já produzida sobre os coletivos, que objetiva conhecer um pouco dos sujeitos, realidades e anseios que os permeiam.

\section{Identidade ou identidades? O emergir de novos espaços, sujeitos e questões}

Devido aos objetivos da pesquisa e aos limites inerentes a um artigo, esse bloco não tem objetivo de esgotar ou apresentar todos os enfoques relacionados a questão do sujeito e das identidades produzidas a partir dos paradigmas da modernidade e pós-modernidade. Vale também destacar que apesar desses paradigmas gerarem controversas no campo das ciências sociais, sobretudo por se tratar de importações eurocêntricas utilizadas para analisar o contexto latino-americano, nos ajudam a entender as mudanças nos campos das interações sociais, abarcando também as questões identitárias.

A questão inicial que colocamos é: como reconhecer as diferenças e particularidades? Laclau $(1993 ; 2011)$ nos ajuda nessa tarefa ao demarcar a impossibilidade concreta e finita de uma subjetividade multifacetada, bem como de uma identidade autocentrada. A compreensão dessa impossibilidade se inicia a partir da discussão do que vem a ser a categoria sujeito. Spink (2011:17) aponta que a palavra indivíduo tende a remeter a sujeito, mas a partir dos estudos de Foucault, essas distinções não devem ser vistas de forma tão fáceis: "Sujeito é a nomenclatura do léu semântico, pois ora é sinônimo de assujeitamento, de ser passivo diante de processos sociais impositivos; ora é sinônimo de possibilidade de subjetivação, de ter consciência de si”. Para Fonseca (2003), o termo sujeito é utilizado para designar o indivíduo preso a uma identidade que reconhece como sua, constituído pelos processos de subjetivação. Esses processos em conjunto com os de objetivação explicitam por completo a identidade do indivíduo moderno.

O início do reconhecimento da existência de "sujeitos", diferente da figura de um "Sujeito" único e absoluto, composto por apenas uma identidade, produzido e criado pelo iluminismo, muda as reflexões acerca de como devemos compreender quem realmente somos. Laclau observa que a lógica de definição do universalismo surgiu a partir do cristianismo, da relação entre Deus e sua totalidade e da razão humana que é inalcançável da de Deus. A partir desse pensamento surge o "agente privilegiado da história", no qual o autor o descreve sendo: 
[...] aquele cujo corpo particular era a expressão de uma universalidade que o transcendia. A ideia moderna de uma "classe universal" e as várias formas de eurocentrismo nada mais são do que os efeitos históricos longínquos da lógica da encarnação. [...] Porque a modernidade foi, no limite, em grande medida, uma tentativa de interromper a lógica da encarnação. Deus, origem absoluta de tudo que existe, foi substituído em sua função de fiador universal da Razão; só que um fundamento e origem racionais têm lógica própria, o que é muito diferente da de uma intervenção divina - a principal diferença é que os efeitos de uma fundamentação racional têm de ser inteiramente transparentes à razão humana (Laclau, 2011:51).

O iluminismo traçou uma fronteira entre o presente e o passado, passado esse marcado por mitos, dogmas e domínios de erros e loucuras do homem, onde o futuro racional existiria a partir do "homem", "Sujeito", desprendido de algo superior a ele. Laclau observa que o universal foi encarnado ao homem, habitando seu próprio corpo, mas essa encarnação não respeitou as particularidades dos receptáculos que se diziam donos e produtores da razão.

A cultura europeia do século XIX, que era particular de alguns povos, utilizou do "universalismo europeu no qual havia construído sua identidade precisamente pelo cancelamento da lógica da encarnação e, com resultado, da universalização de seu próprio particularismo" (Laclau, 2011:52). A expansão imperialista da modernidade se inicia, vendida e apreciada como fonte e função civilizatória universal.

A modernidade não se trata apenas de uma forma de pensar, evoluir, desapegar, suas transformações e ações impactaram diferentes campos que vão além dos sujeitos. Habermans reflete que:

[...] no mundo moderno a emancipação transformou-se em privação de liberdade, pois a força desencadeadora da reflexão se autonomizou, e ela só é capaz de realizar a unificação por meio da violência de uma subjetividade que subjuga. $\mathrm{O}$ mundo moderno padece de falsas identidades, porque tanto no cotidiano como na filosofia eleva algo condicionado a absoluto (Habermans, 2000:48).

Aqueles que resistiam e se apresentavam no campo da luta entre identidades e culturas particulares eram vistos como povos sem histórias e no fim incapazes de representar o seu universal. Dentro desse campo de disputas existem diversas identidades.

A heterogeneidade presente no mundo fez da modernidade um projeto paralelo para muitos povos e, consequentemente, deu margem para abertura de críticas, questionamentos a respeito de suas potencialidades e objetivos. Assim:

[...] ao fundar a possibilidade do conhecimento objetivo, do discernimento moral e da avaliação estética, a razão crítica não só assegura suas próprias faculdades subjetivas e torna transparente a arquitetônica da razão, mas também assume o papel de um juiz supremo perante o todo da cultura (Habermans, 2000:28-29). 
A crítica ao idealismo subjetivo e à ascensão do homem pode ser vista simultaneamente como uma crítica à modernidade e às suas ferramentas, que não conseguiram alcançar as máximas em grande parte dos países não centrais, não cumprindo todas suas promessas, o que deixa marcas severas na ordem social e cultural desses locais.

Aceitar a fragmentação, o pluralismo e a autenticidade de outras vozes e outros mundos traz um agudo problema de comunicação e dos meios de exercer o poder através do comando. A maioria dos pensadores pós-modernos estão fascinados pelas novas possibilidades de informação, produção, análise e transferência de conhecimento proposto por esse paradigma, que tem resultado na produção de um conhecimento sem amarras, com enfoque na diversidade (Harvey, 2007).

As discussões sobre fragmentação e alteridade, que embasam a pós-modernidade formam pensamentos importantes sobre os caminhos que devem ser seguidos para uma sociedade mais diversa, que atenda a todas as particularidades. Na busca pela liberdade, Santos (2013:93) crê que, o que falta concluir da modernidade não pode ser mais feito em termos modernos sob pena de "nos mantermos prisioneiros da mega-armadilha que a modernidade nos preparou: a transformação incessante das energias emancipatórias em energias regulatórias".

A racionalização, organização social, progresso científico e tecnológico, e a difusão do ensino universal nas sociedades ocidentais avançadas advém da modernidade como consequência da busca pela garantia da liberdade dos sujeitos, vindo figurar como forma de amarra regulatória, engessando e limitando a ação e o desenvolvimento humano. A insuficiência do pensamento e do modelo hegemônico ocidental evidenciou a existência de outras identidades que antes se encontravam oprimidas e invisíveis ao campo produtor de conhecimento. Por sua vez, a pós-modernidade e os conhecimentos que partem dela trazem um novo horizonte para a compreensão do auxílio de grupos antes marginalizados e esquecidos, possibilitando uma maior integração dos que antes não faziam parte desse ciclo representativo. Laclau (2011:154) conclui que:

[...]se a passagem da modernidade para a pós-modernidade ocorresse no nível de seus horizontes sociais e intelectuais, tal movimento não implicaria o colapso de todos os objetos e valores contidos no horizonte da modernidade.

Desse modo, o que teríamos seria uma "reformulação" a partir de outras perspectivas, nas quais devemos nos distanciar das exigências necessárias da razão trazidas pelo 
iluminismo e buscar construções sociais mais reflexivas e pragmáticas. Nem mesmo as promessas de um futuro ilimitado proposto pela modernidade foi suficiente para conter o clima intelectual das últimas décadas, no qual uma crescente e generalizada consciência da existência dos limites da razão iluminista ganhou força (Laclau, 1993).

As infinitas possibilidades apresentadas pelo paradigma pós-moderno afetaram não apenas o "sujeito", mas também as identidades que os formam. Hall aponta o seguinte questionamento: $\mathrm{O}$ que existe? Um eu coletivo, capaz de estabilizar, fixar ou garantir o pertencimento cultural ou uma unidade imutável que se sobrepõe a todas as outras diferenças?

[...] Essa concepção aceita que as identidades não são unificadas; que elas são, na modernidade tardia, cada vez mais fragmentadas e fraturadas; que elas não são, nunca singulares, mas multiplicamente construídas ao longo de discursos, práticas e posições que podem se cruzar ou ser antagônicos. As identidades estão sujeitas a uma historicização radical, estando constantemente em processo de mudança e transformação (Hall, 2014:108).

A identidade se apresenta como um conceito que se relaciona diretamente com o poder e ao mesmo tempo com a exclusão, "a constituição de uma identidade social é um ato de poder e essa identidade como tal é poder" (Laclau, 1993:48). Para o autor, a condição de existência de uma certa identidade é o mesmo que estudar os mecanismos de poder que a tornam possível. E para além do poder, "as identidades se constituem baseadas no ato de excluir algo e de se estabelecer uma violenta hierarquia entre dois polos resultantes branco/negro, mulher/homem" (ibidem:49). O branco e o homem são postos em referência como "ser humano", a identidade base, o parâmetro para as demais, no qual aqueles que não estão inseridos nesse grupo são automaticamente excluídos. Dessa forma, as unidades que as identidades proclamam são, na verdade, construídas no interior do jogo do poder e da exclusão (Hall, 2013).

A partir da percepção de que todas as identidades funcionam por meio da exclusão, da construção discursiva de um exterior constitutivo e da produção de sujeitos abjetos e marginalizados, aparentemente fora do campo simbólico, do que viria ser ideal, formam a base para os questionamentos sobre a viabilidade da existência de uma "identidade global" (Butler, 2011; Hall, 2013). Mesmo com a existência de uma luta contra a manipulação e a dominação, os objetivos e metas são específicos para determinados grupos. A resistência passa a se fragmentar, não sendo mais "a resistência", mas "as resistências" (Santos, 2013; Hall, 2019). 
Laclau (2011:54) afirma que "o universal nada mais é do que um particular que em algum momento se tornou dominante, que não há nenhuma possibilidade de alcançar uma sociedade reconciliada”. Nas sociedades pós-modernas passam a proliferar outros particulares que já não se sentem contemplados com o universal já estabelecido.

As lutas políticas e sociais dos anos 1990 parecem nos confrontar com uma proliferação de particularismos, enquanto o ponto de vista da universalidade vai sendo colocado posto de lado como um sonho totalitário ultrapassado (Laclau 2011:54).

Contudo, isso não deve ser analisado como uma supremacia das questões particulares e uma negação total das causas universais, mas sim levar em consideração que o universal só existe por conta do particular e o particular devido ao universal. A cultura e a identidade são estruturas que constituem o social e nos permitem compreender as ações coletivas contemporâneas não somente a partir do contexto no qual os atores estão inseridos, mas também as motivações por trás da forma com que se organizam, agem e creem - que refletem a subjetividade dos indivíduos e também as diferenças que carregam.

Laclau (1989) enfatiza que o agente social deve ser abordado com pluralidade, o que depende das várias posições dos sujeitos, dentro de várias formações discursivas. Esse novo agente social é a marca das sociedades pós-modernas, e para melhor compreendê-lo é necessária uma abordagem teórica através da noção do sujeito, como um agente descentralizado e "destotalizado".

Essa noção de sujeito mostra sua interação dentro das ações que participam em uma estrutura discursiva essencialmente instável, de modo que é possível perceber como essas diferentes posições agem no campo da "diferença" entre elas. É viável um diálogo/convivência/conexão desses sujeitos mesmo sendo diferentes uns dos outros, e a sua relação só se torna concreta a partir de conexões variáveis e historicamente contingentes. Laclau (1993:68) reitera que:

[...] um mundo organizado em torno das relações sociais tradicionais é um mundo em que as possibilidades de variação e transformação são estritamente limitadas: os homens não podem escolher e construir sua própria vida porque ela já foi organizada por um sistema social que os precede. Pelo contrário, o deslocamento das relações sociais de um fenômeno como o de a mercantilização, gera, provoca resistências que jogam na arena histórica novos atores sociais que, precisamente por se moverem em um campo deslocado, devem reinventar constantemente suas próprias formas sociais. 
A organização desses sujeitos compostos por diversificadas questões que mesclam temas identitários, culturais e sociais demonstra a capacidade de conexão e a dificuldade de mudança. Devido a sua inserção em uma ordem social já definida, é a partir das mudanças que surgem no sistema social que os atores buscam novos meios de participação.

A necessidade de se afastar da premissa da unidade ainda é vigente, mas com a produção de novos paradigmas ela tem sido cada vez mais confrontada com a premissa alternativa da pluralidade, da diversidade, da fragmentação e da heterogeneidade. Laclau (2011:52) afirma que "o universal havia encontrado seu próprio corpo, mas este ainda era o corpo de uma particularidade". Todo conhecimento que se baseia na lógica da universalidade parte de uma particularidade, é uma relação da qual não sai uma única resposta totalizadora e definitiva.

A necessidade de um regionalismo nunca foi tão urgente em um país de grande extensão e multiculturalidade, onde cada região tem características únicas e sujeito diversos. Para que se possa recriar um nacional mais plural, a regionalização é necessária (Ianni, 1999). As diferenças, deficiências e contradições nos revelam um possível Brasil pós-moderno nos aspectos identitários, onde os pensamentos binários já não possuem espaço na contemporaneidade e as influências não ocorrem apenas entre regiões, mas os modos de representação simbólica de diversos países e continentes se inter-relacionam e formam diferentes modos de vida (Canclini, 2008).

As discussões sobre a modernidade e pós-modernidade nos apresentam um cenário rico nos estudos das ciências humanas, os dois paradigmas nascem da necessidade de construir e pensar para além do que já se foi estabelecido. O uso da ciência, a valorização do homem, a criação de ferramentas que contribuíssem para o desenvolvimento humano, social e político fizeram da modernidade um estilo de vida, costume e organização que possibilitou a humanidade crescer sem as amarras dogmáticas religiosas, por meio da liberdade, igualdade e solidariedade, mas pecou no andamento do seu projeto que beneficiou poucos e violentou vários. Pensar a sociedade por meio dos prefixos "pós" é adentrar em um campo de incertezas, embates e divergências, mas o "pós" não pode ser pensado apenas em aspectos negativos, ele nos leva também a um misto de continuidade e crítica que nos possibilita, de certa forma, acompanhar as mudanças sociais.

As várias concepções produzidas acerca do que é a pós-modernidade confluem na ideia de "novo", "reinvenção" e "superação", o que nos faz lembrar os ideais da modernidade. Mas a diferença está na reconstrução e ressignificação dos sujeitos que buscam superar a 
homogeneização, apresentam suas diferenças, pluralidades e diferentes formas de ações, e assim, buscam produzir suas próprias concepções e ideias.

Dentre todas as questões apresentadas sobre as mudanças propostas pela pósmodernidade e o impacto que esse paradigma exerce na configuração dos sujeitos na contemporaneidade, os agrupamentos de pessoas que se auto intitulam "coletivos" se apresentam como respostas/consequências da valorização das particularidades e a necessidade de se encontrar caminhos diferentes dos convencionais, na busca pela superação das amarras regulatórias impostas pelo universalismo moderno.

Os coletivos configuram-se em agrupamentos marcados por múltiplas identidades, composto por várias temáticas, no qual, em suas falas, não se predomina uma identidade central, mas diferentes questões. Por meio da interseccionalidade - ferramenta teórica e metodológica usada para pensar a inseparabilidade estrutural entre raça, gênero e classe, mas que com o tempo tem abarcado outras formas de intersecções de identidades sociais que não só as geridas por essas três variáveis explicativas - com diferentes marcadores sociais da diferença, geram novos antagonismos, buscam se afastar da premissa da unidade e trazem o conceito da diversidade de forma mais efetiva dentro do campo das ações coletivas e consequentemente ao meio social.

\section{O que existe por trás dos coletivos?}

Os coletivos estão se tornando figuras relevantes no campo das ações coletivas, especialmente nas pesquisas no âmbito das ciências sociais, que têm mostrado interesse em estudar essas novas interações. A multidimensionalidade dos sentidos que podem ser atribuídos a eles, varia de acordo com os contextos sociais, históricos e geográficos em que estão inseridos. Eles, da forma que são caracterizados pelos estudos, parecem organizações autônomas, menos estruturadas em termos burocráticos e institucionais, não possuem base social com fortes laços de identificação e refletem uma lógica organizacional de socialização baseada no compartilhamento de ideias entre "ativistas", recusam a ideia de "liderança" e estão de costas para o Estado e formas tradicionais de organização (Mesquita, 2008; Gohn, 2017; Perez; Souza, 2017; Peralva, 2017; Lima, 2018). Todos esses aspectos apresentados indicam a necessidade de se investigar e analisar a incidências dessas características nos coletivos que se formam na Região Nordeste, já que todos esses trabalhos analisam coletivos da região sul e sudeste. 
É nítido que a análise das questões feitas a seis coletivos de seis estados da região Nordeste não são suficientes para compreendermos de forma aprofundada sobre "todos" os coletivos ou quem são as pessoas que formam esses agrupamentos, mas nos dar um norte sobre algumas questões postas como importantes para essas organizações que se formam na região, e nos ajuda a perceber algumas necessidades e anseios daqueles que escolhem os coletivos como forma de organização.

\section{O que eles entendem por coletivo?}

Ao nos atentarmos para a diversidade de sujeitos e temas, é importante saber o que os participantes entendem por "Coletivo" e quais os sentidos atribuídos a esta palavra tão recorrentemente referida nos últimos anos e que virou símbolo (marca) de organizações.

Para o Coletivo do Maranhão a compreensão do que é coletivo está ligada à união, "a ideia de coletivo como algo que une pessoas conectadas por algo em comum, sem necessariamente haver um fim de interesse econômico, ou coisa do tipo".

O Coletivo do Piauí afirma que a compreensão do conceito de coletivo, "vai desde a questão do coletivo político até a minha vida, pois tudo em coletivo é mais fácil, tendo outras pessoas para partilhar nossas alegrias, nossas tristezas, nossa confiança".

O Coletivo de Pernambuco segue a mesma linha dos coletivos anteriores e traz a reafirmação do trabalho em conjunto, ao afirmar que:

[...] a gente entende por coletivo, um grupo capaz de se auto organizar, independente, que tem como norte principal o consenso entre seus membros, a gente pensa também em uma forma de estabelecer alguns princípios para o coletivo, pois acreditamos que precisamos de princípios para moverem nossas ações e principalmente a vontade de trabalhar em conjunto, a gente entende coletivo como vontade própria de trabalhar em conjunto, de se propor a trabalhar em conjunto (Coletivo Pernambuco, 2019).

Para o Coletivo de Alagoas, a compreensão do que vem a ser coletivo é "quando pessoas entram em consenso em se unir almejando algo em comum, no nosso caso: a mudança social, que só acontecerá se for organizada coletivamente em prol da classe trabalhadora". O Coletivo do Rio Grande do Norte afirma que a percepção de coletivo é "um espaço auto organizado de luta". Já a visão do que vem a ser coletivo, do Coletivo da Bahia, é "um conjunto de pessoas que se unem em prol de um objetivo, que não se limita nelas mesmas". 
A partir da fala dos seis entrevistados é possível verificar dois tipos de percepções do que é coletivo. Para os coletivos de Pernambuco, Alagoas e Bahia a sua compreensão está mais voltada à união, ao trabalho em conjunto em busca de algo comum. Eles reiteram o pensamento compartilhado aplicado aos Novos Movimentos Sociais que se unem por meio de questões subjetivas e heterogêneas (Gohn, 2017).

Os outros quatro coletivos, Maranhão, Piauí, Rio Grande do Norte têm em suas falas um enfoque voltado para a luta, política e economia. A união do grupo não está voltada apenas para as questões econômicas e corrobora com uma das características dos Novos Movimentos Sociais ${ }^{6}$ que inovam discutindo e apresentando outras temáticas desde os anos de 1960.

O Coletivo de Alagoas traz na sua fala a união e algo em comum que seria a mudança social. Ela só aconteceria com a organização coletiva da classe trabalhadora. Essa fala nos remete à lógica da hegemonia apresentadas por Laclau e Mouffe (2005), na qual a hegemonia só seria alcançada pelos grupos por meio de articulação de classes e grupos sociais. A busca pela mudança social através da união da classe trabalhadora, na fala de um coletivo, no ano de 2019, traz a reflexão acerca da ressurgimento de questões do trabalho que tinham deixado de se tornar centrais com a formação dos Novos Movimentos Sociais que emergem a partir de 1960-1970, mas que em 2019 continuam vivas em alguns coletivos que se formam no Nordeste do Brasil.

Os coletivos do Piauí e o Coletivo do Rio Grande do Norte reafirmam a formação de organizações coletivas que compreendem sua constituição por meio da "luta", no qual levam a entender a existência de opositores e questões que precisam ser superadas. O embate está diretamente ligado a esses coletivos, o que os relaciona com a noção de conflito proposta por Tarrow (2009), que compreende os movimentos sociais como desafios coletivos baseados na solidariedade e objetivos comuns, e se sustentam por meio de uma interação de oposição. Mas esse conflito não está relacionado exclusivamente com relação ao uso da força, o conflito acontece, segundo Tilly (2010), também quando ocorre divergência de interesse, demandas ou reivindicações que provoquem qualquer tipo de desentendimento.

\footnotetext{
${ }^{6}$ As mudanças na sociedade ao longo do século $\mathrm{XX}$, teriam alterado não só a natureza do capitalismo, mas também as formas de mobilização coletivas. Os novos sujeitos não seriam classes, mas grupos marginais em relação aos padrões de normalidade sociocultural, esses novos movimentos sociais se transformariam em organizações voltadas para questões identitárias (movimento feminista, ambientalista, negros, sexuais, entre outros). O interesse não estaria em confrontar diretamente o Estado ou até mesmo conquistá-lo, mas com o objetivo de questionar costumes, e propor uma mudança no âmbito da sociedade civil, em busca de novos modelos participativos a partir de formas particulares de resistência (Melucci, 1989; Touraine, 2006; Gohn, 2008).
} 
Ainda sobre a dimensão conflitiva, para Melucci (1989), o conflito é uma relação entre atores opostos, lutando pelos mesmos recursos aos quais ambos dão valor. A solidariedade é a capacidade de os atores partilharem uma identidade coletiva. Essa mesma identidade coletiva contribui para a criação desses coletivos fazendo com que eles tenham capacidade de se unirem e buscarem demandas comuns a todos. A união decorrente da solidariedade e a possibilidade de construir locais mesclados por diferentes identidades fazem dos coletivos, para esses entrevistados, o "termo" que melhor defini esse espaço plural composto por diferentes sujeitos.

\section{Por que decidiram se organizar em coletivos e não em outro tipo de organização?}

Com a enorme quantidade de formas organizativas presentes e atuantes na sociedade civil, por que os sujeitos criam novos repertórios de ação e organização? Saber o porquê de escolherem os coletivos e não outro tipo de organização nos ajuda a compreender a fundo as mudanças ocorridas na forma de agir dos sujeitos.

Quando questionados sobre o motivo de decidirem se organizar em coletivo e não em outro tipo de organização, o Coletivo do Maranhão respondeu prontamente que "tem muito a ver com a ideia de criar algo mais livre, que se encaixasse dentro das possibilidades de cada integrante do grupo, estando como coletivo por exemplo, que não estabelece uma 'função específica para cada integrante"”.

Para o Coletivo de Pernambuco, a forma organizativa em coletivo proporciona uma "maior facilidade de sair do espaço acadêmico, um núcleo de estudo ou uma organização de alguma coisa, poderia semanticamente trazer uma outra perspectiva para as pessoas de fora.". O Coletivo do Rio Grande do Norte fez essa escolha devido à "fluidez do ambiente universitário, as pessoas são bem diferentes, cada um com uma construção, e acho que quando você pensa em um movimento social mais rígido...”.

Os três coletivos convergem entre si no que diz respeito à escolha de um coletivo como forma organizativa. É observado nos três que os coletivos apresentam uma estrutura mais livre, dinâmica, não são rígidos, em que eles podem efetuar diversas atividades e são capazes de acolher diversas heterogeneidades. Para eles isso não poderia ser possível por meio de um partido político, movimento social tradicional ou sindicato. Isso demonstra as diferenças entre os coletivos e as demais organizações da sociedade civil que foram apontadas por alguns autores como Maia (2013), Gohn (2017) e Perez (2018). 
Uma questão evidente, apontada pela literatura sobre coletivos, é a descrença nas instituições e nos meios participativos frutos do modelo da democracia representativa, assim como busca por essas organizações mais autônomas e distantes dos modelos clássicos (Gohn, 2017; Alonso, 2017; Peralva, 2017; Perez, 2018).

A juventude tem contestado e renovado as práticas e valores estabelecidos por meio de sua cultura. Essa mudança se dá pela elevação dos níveis de escolaridades dos jovens, seu idealismo e acesso às informações na internet (Peralva, 2017). Os jovens passaram a participar mais ativamente e a se sentirem seguros em questionarem e contestarem o que não concordam, tendo como resultado um esvaziamento dos movimentos de representação estudantil e outras formas tradicionais relacionadas à juventude (Mesquita, 2008). A crítica às formas universalistas e tradicionais faz parte da evolução dos sujeitos contemporâneos, que passam a questionar também as configurações organizativas criadas e impostas na modernidade.

Os outros dois coletivos trazem um aspecto mais voltado para o político, e se aproximam mais daquilo que foi apontado por Gohn (2017) como agrupamentos de contestação que atuaram nas manifestações de junho de 2013. O Coletivo da Bahia afirma que devido ao "formato e possibilidade que o coletivo proporciona para a atuação e diálogo com as mulheres e os locais que elas estão inseridas, nos bairros, locais de trabalho e estudo e, justamente pelo coletivo não limitar nosso espaço de militância". Por fim, o Coletivo Piauí afirma que o coletivo é "muitas vezes a porta de entrada para outra organização, como o coletivo é integrado pela juventude, vejo como o início de tudo para que as pessoas tomem consciência de classe e organização".

A partir da fala dos dois coletivos é possível notar que a autonomia, vista no sentido de uma não relação com o Estado, sindicatos, movimentos sociais clássicos, partidos políticos e demais formas de ações coletivas já consolidadas, se torna uma das razões centrais da escolha em se organizar por meio de um coletivo. Os sujeitos buscam liberdade, igualdade, justiça e independência não só de um governo, mas também de estruturas totalizantes como sistema capitalista e projetos totalitários que são marcas da modernidade (Gohn, 2017; Santos, 2013). A unidade desses coletivos se mantém por meio da solidariedade baseada em várias identidades, a presença dessas formas de construção coletivas nos apresentam possíveis novas formas de modalidades de ação política que não só as amparadas por instituições (Melucci, 1989; Day, 2005; Augusto; Rosa; Resende, 2016).

Além do aspecto da autonomia presente nos coletivos, também é possível observar em suas falas o desejo de se fazer mais, de ir além do que é proposto; a política passa a ser foco 
do ponto de vista de uma cultura política na qual as inovações democráticas estão diretamente relacionadas com as experiências dos movimentos sociais (Gohn, 2019). Muitos dos participantes dos coletivos tiveram experiências em outros tipos de movimento como o estudantil. Como o destacado pelo Coletivo Piauí, os coletivos podem representar uma porta de entrada para inserção e preparação da juventude para o ingresso em formas de organização mais tradicionais.

Os coletivos têm a capacidade de integrar e interagir com espaços menores, locais, o que ocorre com o Coletivo da Bahia, contrapondo os movimentos socias, que na atualidade possuem sua abrangência maior, muitas vezes não conseguindo alcançar lugares considerados até mesmo "insignificantes" para os que se organizam em formas de organização consolidadas.

\section{Os coletivos possuem ou não projetos?}

O objetivo buscado por esses coletivos pode nos elucidar as necessidades que eles observam como urgentes e o que os levam a se organizar e também a demonstrar o porquê não buscar isso por meio de outras formas tradicionais de ações coletivas (movimentos sociais, partidos políticos, associações, entre outras).

Quando questionados sobre o objetivo do grupo, Coletivo do Maranhão respondeu "Possibilitar o encontro entre mulheres cantoras, compositoras, intérpretes, musicistas e produtoras culturais de São Luís- MA e demais cidades próximas, e desse encontro fortalecer o cenário local da música para mulheres". O Coletivo de Pernambuco afirmou "que a gente tem essa finalidade de fortalecer a luta racial na cidade, principalmente dos jovens".

A fala do Coletivo do Piauí foi "fazer com que a sociedade seja um pouco menos individual e que as pessoas vejam o comunismo como a saída de um capitalismo que não tem mais pra onde crescer." O coletivo do Rio Grande do Norte, seguindo o mesmo viés político afirmou: "lutar pela construção de uma democracia socialista, que a gente consiga através de um diálogo democrático conciliar situações de alguns setores, como a classe trabalhadora e os estudantes". Já o Coletivo de Maceió, com objetivo voltado para as questões de classe, diz que "O objetivo central é disputar a consciência de classe dessas pessoas e mostrar a importância de se organizar politicamente na luta contra a opressão e exploração das mulheres da classe trabalhadora pela superação da sociedade de classes". O coletivo da Bahia não respondeu à pergunta. 
Dentre as cinco falas, é possível perceber objetivos distintos e até mesmo específicos, voltados para as necessidades de cada coletivo. Os coletivos do Maranhão e Pernambuco trazem questões identitárias fortes, como gênero e raça, o que nos leva a identificar a necessidade de ações voltadas para essas questões em suas localidades. Os coletivos do Piauí, Rio Grande do Norte e Maceió apresentam objetivos mais voltados as questões políticas mesmo que relacionado a outros marcadores, como gênero, sexualidade e classe. Os projetos propostos por esses coletivos aplicam a ideia de interseccionalidade - gênero, raça, classe cada vez mais presente nos agrupamentos contemporâneos, reiterando a formação de espaços compostos não apenas por meio da união de uma única particularidade, mas de várias.

\section{Existe um perfil dos participantes que compõe o grupo?}

Saber quem são as pessoas que formam esses coletivos é de suma importância. Quando questionados sobre o perfil dos participantes que compõe o grupo, os coletivos deram as seguintes respostas: para o Coletivo do Maranhão, "a única determinante para que se faça parte do grupo é que a integrante seja mulher e tenha alguma relação com o meio musical”. O Coletivo Piauí possui participantes bastante heterógenos que vão desde "pessoas prestes a ingressar na universidade e as que já concluíram o ensino superior. A grande maioria são pessoas LGBT negras, entre homens e mulheres é bem nivelado”. Seguindo a perspectiva da heterogeneidade dos participantes, o Coletivo do Rio Grande do Norte afirma que "tem muitos homens brancos e héteros, inclusive são os mais antigos no coletivo, mas tem o LGBT, tem a $\operatorname{poc}^{7}$ da periferia e de classe média, tem a mulher negra.”. O Coletivo de Pernambuco é todo formado por pessoas negras. O Coletivo de Alagoas afirma que seu coletivo é formado na sua grande maioria por professoras da educação básica e do ensino superior. Já o Coletivo da Bahia se concentra em mulheres trabalhadoras ou em formação.

A luta pelo reconhecimento, das múltiplas identidades do sujeito multifacetado-se apresenta como uma das marcas mais importantes dos coletivos analisados. Eles discutem diversas temáticas, resultantes da heterogeneidade de sujeitos que os formam. Dos seis coletivos entrevistados é perceptível o enfoque na juventude, mas isso não significa que pessoas mais velhas não participem. Há uma presença forte das questões de gênero nesses

\footnotetext{
${ }^{7}$ Gíria utilizada pela comunidade LGBT que atualmente possui dois sentidos. No primeiro a palavra tem sido usada para denominar LGBTs do sexo masculino, na faixa etária dos 20 anos, assumidos, dotados de características femininas e que possuem preocupação com a aparência e moda, mas não necessariamente a pessoa tem que cumprir todos esses requisitos. O segundo sentido está relacionado à origem do termo da "bicha pão com ovo", ou ainda tem a ver com os gays que andam de salto e reproduzem o som de poc, poc, poc.
} 
coletivos, com muitos coletivos voltados para mulheres e suas respectivas ocupações, demonstra a grande e efetiva participação feminina fora da esfera privada, na luta por participação, melhores condições de trabalho e direitos. A raça também constitui um marcador importante na configuração dos participantes que formam esses coletivos, como as questões sexuais e socioeconômicas.

Por meio da multiplicidade de identidades é possível perceber quais são os marcadores sociais da diferença que atravessam esses coletivos. Os coletivos não discutem apenas uma única pauta, uma vez que ocorre uma interseccionalidade com outros marcadores que fazem parte das suas questões de lutas e complementam suas demandas (Moutinho, 2014). "A interseccionalidade impulsiona a diversificação temática no interior dos coletivos que, diante da constatação de desigualdades têm relação com diversos marcadores sociais, acabam adotando tais discussões nas lutas cotidianas" (Rios; Perez; Ricoldi, 2018:43). Os múltiplos marcadores sociais da diferença presente nos coletivos têm possibilitado a abrangência do estudo da categoria intersececcionalidade, enquanto identidade coletiva dos agentes envolvidos nos múltiplos e decentralizados ativismos políticos contemporâneos (ibidem).

\section{A falta de discussões de temáticas sobre raça, gênero, classe, política influenciou a criação do agrupamento?}

Muitas vezes o início de algum projeto, agrupamento/organização começa devido à ausência de algo. Saber se a ausência da discussão de algumas temáticas na vida daqueles que formam os coletivos, influencia ou não na construção desses agrupamentos, é poder perceber as lacunas que precisam ser preenchidas nos diferentes tipos de ações coletivas na contemporaneidade.

Uma das características apontadas pela literatura sobre os coletivos está na sua heterogeneidade e na adoção de múltiplas pautas que irão constituir o agrupamento. O termo, interseccionalidade, tem sido algumas vezes remetido aos coletivos. De acordo com Hirata (2007), a interseccionalidade é um termo que designa a interdependência das relações de poder, raça, sexo e classe. Para Crenshaw (1994), ela leva em conta as múltiplas fontes de identidade, embora não tenha a pretensão de propor uma teoria globalizante da identidade. Dessa forma:

A interseccionalidade remete a uma teoria transdisciplinar que visa apreender a complexidade das identidades e das desigualdades sociais por intermédio de um enfoque integrado. Ela refuta o enclausuramento e a hierarquização dos grandes eixos da diferenciação social que são as categorias de sexo/gênero, classe, raça, etnicidade, idade, deficiência e orientação sexual. O enfoque interseccional vai além 
do simples reconhecimento da multiplicidade dos sistemas de opressão que opera a partir dessas categorias e postula sua interação na produção e na reprodução das desigualdades sociais (Bilge, 2009:70 apud Hirata, 2007:62-63).

Os movimentos sociais, os partidos políticos e demais formas clássicas de ações coletivas, na sua grande maioria estabelecem uma hierarquização dos grandes eixos de diferenciação, a exemplo da luta de classes ou outras questões mais específicas, deixando de lado demais temáticas que poderiam ser trabalhadas em conjunto. Uma das razões da proliferação dos coletivos está na multiplicidade de temáticas, o que é insuficiente nos demais tipos de organizações.

Majoritariamente, na fala dos cinco coletivos que responderam às questões, a falta de discussão em espaços importantes, a exemplo, o próprio âmbito familiar, midiático, político, os espaços tradicionais de participação como partidos políticos, sindicatos e associações, foi imprescindível na formação desses agrupamentos. O coletivo do Piauí afirma que "foi justamente dentro da faculdade, lendo, que fui conhecendo sobre coletivos. Conversando com outras pessoas me influenciaram a participar e a me organizar assim”. O coletivo do Rio Grande do Norte afirma que, para muitos dos seus participantes, essas discussões já eram corriqueiras, mas que para outros a sua organização possibilitou a inserção de discussões que demais pessoas do grupo não tinham acesso, "é legal ver que tem participantes do curso de arquitetura, engenharia, e são cursos que estão distantes dessa lógica de pensamento social, crítico, mas buscam no coletivo uma forma de discutir isso". As universidades mostram-se locais importantes não só de produção de conhecimento, mas também de interação e percepção de outros significantes que eram externos ao sujeito.

O coletivo de Pernambuco traz uma percepção diferente, a da falta de discussão:

[...] é muito raso, muito vago o que a gente vê sobre raça, sexualidade, feminismo e tal, então a gente se sentiu impulsionado por essa falta de debate. No meu curso por exemplo, que é Ciência Política, eu tenho apenas um professor negro no departamento inteiro, acho que são 25 professores e eu tenho apenas um professor negro [...]. Mas isso também foi um dos motivos, porque eu me perguntava: "poxa, eu não tenho um professor negro? Não estudei com um negro em toda graduação?" Eu me perguntava como poderia estar no curso de Ciência Política, debatendo política, teoria política e não ter nenhuma perspectiva a respeito da negritude, e que o racismo é estrutural, todo mundo sabe disso (Coletivo Pernambuco, 2019).

Reafirmando o que foi apontado pelo coletivo de Pernambuco, mas trazendo outra temática, o coletivo da Bahia afirma que: 
que surgiam ali deveriam ir para outros espaços e alcançar outras pessoas que muitas vezes não estão inseridas no ambiente acadêmico (Coletivo Bahia, 2019).

A não discussão de temáticas tão importantes como classe, gênero, sexualidade, raça, entre outras, são causas importantes que geram a formação dos coletivos. Isso nos leva a identificarmos algumas deficiências em ações coletivas tradicionais (movimentos sociais, partidos políticos, associações, sindicatos) em contemplarem diferentes temáticas e assim outras tantas heterogeneidades. A busca pela individualidade não pode ser confundida com o individualismo, ela deve pautar a luta pelo reconhecimento e sua consequente construção de diversidade em um contexto político mais amplo.

\section{Considerações finais}

A discussão proposta nesse trabalho teve como objetivo observar algumas características atribuídas aos coletivos, como a multiplicidade de pautas, heterogeneidade e interseccionalidade, resultando na construção de organizações compostas por identidades múltiplas. Antes de chegar à análise específica das cinco questões feitas aos coletivos, foram apresentados diferentes enfoques sobre identidade e sujeito, utilizando como base de análise dois paradigmas: modernidade e a pós-modernidade.

O desafio enfrentado foi compreender esses modelos analíticos, as suas análises sobre tais questões e perceber os caminhos percorridos para a construção e evolução do entendimento do que vem a ser o sujeito, as identidades e os particularismos que constituem a sociedade na atualidade.

A produção do saber contemporâneo, com base nas alterações sociais, continua a permear a constituição do conhecimento, na qual diferentes terminologias são criadas, como: modernidade, pós-modernidade, novos movimentos sociais, novíssimos movimentos sociais, neomarxismo, neoconstitucionalismo, decolonialidade, entre outros. Essa marcha que se inicia com o iluminismo e perdura no imaginário acadêmico até os dias atuais expõe o contínuo desafio de interpretar o passado para compreender o presente. De certa forma, os paradigmas adequados à compreensão e descrição desses novos modos e ações da sociedade ainda se constituem como incógnitas. Porém, esse desconhecimento possibilita criar e recriar diferentes perspectivas de análises de distintas formas de organização que, na maioria dos estudos, aparecem como "novo", a exemplo dos coletivos.

É perceptível que as relações sociais evoluíram, não podendo mais se falar de uma única identidade ou ações coletivas voltadas para uma única pauta, desejo, demanda. Essas 
alterações ficam claras nas falas dos entrevistados quando respondem o questionamento do porquê se organizar em coletivo e não em outras formas de agrupamentos. Os movimentos sociais clássicos, os partidos políticos, as associações e demais formas de organização, apresentam ainda modelos engessados que seguem a linha do universalismo, não sendo suficientes e até mesmo adequados para englobarem a infinidades de particularismos que surgem cotidianamente, e que tem levado muitos a criarem seus próprios grupos, como no caso os "coletivos".

A diversidade de participantes dos coletivos confirma as heterogeneidades presentes na sociedade. As pautas escolhidas por eles demonstram suas necessidade e anseios, além de demonstrar a falta de espaços de discussão delas. Os específicos marcadores sociais da diferença que os atravessam estabelecem os elos de forma interseccional que possibilitam a criação de agrupamentos coesos com relação às demandas, mas são inteiramente distintos quando vistos por meio de uma ótica cultural identitária.

Os coletivos se tornaram agrupamentos importantes na construção da sociedade civil brasileira e apresentam diferentes perspectivas e necessidades. Ainda não é possível produzir um conceito consistente sobre esses agrupamentos, visto que os coletivos têm diferentes configurações, e não se pode reduzir apenas a "coletivos" no sentido geral, pois eles são coletivos tanto em um número reduzido de participantes, quanto em tipos que se agrupam por temáticas diferentes, precisando de uma visão mais exata e dinâmica, longe do aspecto universalista aplicado aos sujeitos coletivos.

Como ficou demostrado, os coletivos têm se apresentado como organizações "novas", com recorrente tentativa de inovação na ação, nas pautas e na participação. Entretanto, afirmar que tudo relacionado a esse tipo de organização é totalmente "novo" não é crível. É dar continuidade aos erros apontados aos estudos que procuram estabelecer teorias que rompam com o passado e que dão novos nomes a coisas velhas. É nítido a presença de elementos tanto da teoria dos movimentos sociais clássico, quanto dos novos movimentos sociais, apresentando de novidade em si, as suas estratégicas de ações. A dinâmica social possibilita espaços nos quais os atores coletivos se reinventam cotidianamente, sempre com a finalidade de lutar por direitos sociais, participação política e reconhecimento, não significando um total rompimento com o passado e o presente.

Por fim, mais pesquisas sobre esse objeto serão necessárias para aprofundar outros aspectos como a disputa interna de poder, a presença de outros tipos de marcadores sociais, a luta pelo poder político-social, as diferenças e as semelhanças das lutas sociais. 


\section{Referências}

ALONSO, Ângela (2017), "A política das ruas: protestos em São Paulo de Dilma a Temer". Novos Estudos, pp. 49-58 [Consult. 11-12-2020]. Disponível em http://dx.doi.org/10.25091/S01013300201700040006

AMADOR, Arthur C.; CASTRO, Eliane D. (2016), "O Coletivo (com preguiça): encontros, fluxos, pausas, artes". Interface, v. 20, n. 56, pp. 267-280 [Consult. 14-12-2020]. Disponível em https://doi.org/10.1590/1807-57622015.0576

ARAUJO, Tânia. B. (2018), "Mesa I - Revisitando a questão regional". Cadernos do Desenvolvimento, v. 1, n, 1, pp. 59-76 [Consult. 14-12-2020]. Disponível em http://www.cadernosdodesenvolvimento.org.br/ojs-2.4.8/index.php/cdes/article/view/329

ASSIS, Larissa. G (2018), "Virada comunicação: como coletivos de comunicação das periferias estão construindo uma nova forma de se comunicar". Revista Anagrama, v. 12, n. 1, pp. 1-10 [Consult. 14-12-2020]. Disponível em https://www.revistas.usp.br/anagrama/article/view/146727

AUGUSTO, Acácio; ROSA, Pablo. O.; RESENDE, Paulo. E. R. (2016), "Capturas e resistências nas democracias liberais: uma mirada sobre a participação dos jovens nos novíssimos movimentos". Revista Estudos de Sociologia, v. 21, n. 40, pp. 21-37 [Consult. 06-11-2020]. Disponíveç em https://periodicos.fclar.unesp.br/estudos/article/view/7581

AVRITZER, Leonardo (2007), "A participação social no Nordeste", in L. Avritzer (Org.), A participação social no Nordeste). A participação social no Nordeste. Belo Horizonte, UFMG, pp. $15-44$.

BIERNACKI, Patrick.; WALDORF, Dan (1981), "Snowball sampling: problems and techniques of chain referral sampling". Sociological Methods \& Research, Thousand Oaks, CA, v. 10, n. 2, pp. 141-163 [Consult. 14-12-2020]. Disponível em https://doi.org/10.1177/004912418101000205

BORDT, Rebecca L. (1990), "How alternative ideas become institutions: the case of feminist collectives". Nonprofit and Voluntary Sector Quarterly, v. 26, n. 2, pp. 132-155. [Consult. 14-122020]. Disponível em https://doi.org/10.1177/0899764097262003

BORELLI, Simone. ABOBOREIRA, Ariane (2011), "Teorias/metodologias: trajetos de investigação com Coletivos juvenis em São Paulo/Brasil". Revista Latinoamericana de Ciencias Sociales, Niñez $y$ Juventud, v. 1, n. 9, pp. 161-172 [Consult. 07-04-2020]. Disponível em http://www.scielo.org.co/scielo.php?script=sci_arttext\&pid=S1692715X2011000100009\&lng=en\& $\mathrm{nrm}=\mathrm{iso}$

BUTLER. Judith (2011), Bodies that matter: On the Discursive Limits of "Sex". New York, Routledge.

CANCLINI, Nestor. G. (2008), "Latin American Cinema as Industry and as Culture: its transnational relocation. Keynote for presentation", in Transnational Cinema in Globalising Societies: Asia and Latin América. Puebla, México, Universidad Iberoamericana Puebla and Notthingham Ningbo. pp. $29-31$.

COSTA, Diogo F. C.; PAULON, Simone M. (2012), "Participação social e protagonismo em saúde mental: a insurgência de um coletivo". Saúde em debate, v. 36, n. 95, pp. 572-582 [Consult. 14-122020]. Disponível em https://doi.org/10.1590/S0103-11042012000400009 
CRENSHAW, Kimberlé W. (1994), "Mapping the margins: intersectionality, identity politics and violence against women of color", in M, A. Fineman R. Mykitiuk (Orgs.). The public nature of private violence: Women and the Discovery of Abuse. Nova York, Routledge, pp. 93-118.

DAY, Richard (2005), Gramsci is dead: anarchist currents in the newest social movements. Londres, Pluto Press.

DESOUZA, Shaila (2015), "The Strenght of Collective Processes: An 'Outcome Analysis' of Women's Collectives in India". Indian Journal of Gender Studies, v. 19, n. 3, pp. 373-392 [Consult.14-12-2020]. Disponível em https://doi.org/10.1177/097152151201900302

FERREIRA, Glauco (2015), "Margeando ativismos globalizados: nas bordas do Mujeres Al Borde". Estudos Feministas, Florianópolis, v. 23, n. 1, pp. 207-2018 [Consult. 20-07-2020]. Disponível em https://doi.org/10.1590/0104-026X2015v23n1p207

FONSECA, Márcio A. (2003), Michel Foucault e a constituição do sujeito. São Paulo, EDUC.

GOHN, Maria da Glória (2019), "Teorias sobre a participação social: desafios para a compreensão das desigualdades sociais". Cad. $C R H \quad$ v. 32, n. 85, pp. 63-81 [Consult. 22-07-2020] Disponível em https://doi.org/10.9771/ccrh.v32i85.27655

GOHN, Maria da Glória (2017), Manifestações e protestos no Brasil: correntes e contracorrentes na atualidade. São Paulo, Cortez.

GOHN, Maria da Glória (2008), Novas Teorias dos Movimentos Sociais. São Paulo, Loyola.

HABERMANS, Jurgen (2000), O discurso filosófico da modernidade. São Paulo, Martins Fontes.

HALL, Stuart (2014), “Quem precisa da identidade?”, in T. T. Silva (Org.), Identidade e diferença: a perspectiva dos estudos culturais. Petrópolis, Vozes, pp. 103-133.

HALL, Stuart (2019), A identidade na pós-modernidade. Rio de Janeiro, Lamparina.

HARVEY, David (2007), A condição pós-moderna. São Paulo, Edições Loyola.

Hirata, Helena. (2014), "Gênero, classe e raça Interseccionalidade e consubstancialidade das relações sociais". Tempo Social, v. 26, n. 1, pp. 61-73 [Consult. 22-07-2020]. Disponível em http://dx.doi.org/10.1590/S0103-20702014000100005

IANNI, Octavio (1999), A era do globalismo. Rio de Janeiro, Civilização Brasileira.

INSTITUTO BRASILEIRO DE GEOGRAFIA E ESTATISTICA (2010). Censo Demográfico [Consult. 13-08-2019]. Disponível emhttps://censo2010.ibge.gov.br/sinopse/index.php?dados=8

LACLAU, Ernesto (1986), "Os novos movimentos sociais e a pluralidade do social”. RBCS, v. 1, n. 2 [Consult. 19-08-2020]. Disponível em http://anpocs.com/images/stories/RBCS/02/rbcs02_04.pdf

LACLAU, Ernesto (1993), Nuesvas reflexiones sobre la revolución de nuestro tempo. Buenos Aires, Nueva Visión.

LACLAU, Ernesto (2011), Emancipação e diferença. Rio de janeiro, EDUERJ.

LACLAU, Ernesto; MOUFFE, Chantal (2005), Hegemonía y Estrategia Socialista. Buenos Aires, Fondo de Cultura Económica de Argentina. 
LIMA, Elcimar. M. O.; SCHMITZ, Heriberte (2017), "Como os coletivos se mobilizam desde as manifestações de junho de 2013 em Belém", in Anais do $18^{\circ}$ Congresso Brasileiro De Sociologia. Universidade de Brasília. Brasília, SBS, 20 p.

MAIA, Gretha. L. (2013), "A juventude e os Coletivos: como se articulam novas formas de expressão política". Revista Eletrônica do Curso de Direito da UFSM, v.8, n. 1, pp. 58-73 [Consult. 10-082020] Disponível em https://doi.org/10.5902/198136948630

MARQUES, Marcelo; MARX, Vanessa. (2020), "Os coletivos em cena: algumas contribuições para o debate". Simbiótica, v. 7, n. 3, pp. 08-32 [Consult. 07-04-2021]. Disponível em https://doi.org/10.47456/simbitica.v7i3.33691

MELO, Iara; PEREZ, Olivia. (2018), "Coletivos de gênero em Teresina-PI: uma forma de participação das mulheres na sociedade atual", in L. C. X. Luz; O. Perez; R. Marinho (Orgs.). Juventudes, subjetividades e sociabilidades. Teresina, EDUFIPI. pp. 188-210.

MELUCCI, Alberto (1989), “Um objetivo para os movimentos sociais?”. Revista Lua Nova, n. 17 [Consult. 20-08-2020]. Disponível em http://dx.doi.org/10.1590/S0102-64451989000200004

MESQUITA, Marcos. R. (2008), "Cultura e política: a experiência dos coletivos de cultura no movimento estudantil”. Revista Crítica de Ciências Sociais, v. 81, pp. 179-207 [Consult. 10-082020]. Disponível em https://doi.org/10.4000/rccs.660

MIGNOLO, Walter (2010), Desobediencia epistémica: retórica de la modernidad, lógica de la colonialidad y gramática de la descolonialidad. Buenos Aires, Ediciones del Signo.

MORA, Claudia.; RIOS, Marcela (2009), "De Política de Representación a Política de Coalición? Posibilidades de Movilización Feminista em el Chile Post-Dictadura". Polis, Revista de la Universidad Bolivariana, v. 8, n. 24, pp. 133-145 [Consult 12-08-2020]. Disponível em http://dx.doi.org/10.4067/S0718-65682009000300008

MOUTINHO, Laura. (2014), "Diferenças e desigualdades negociadas: raça, sexualidade e gênero em produções acadêmicas recentes". Cad. Pagu, n. 42, pp. 201-248 [Consult. 08-08-2020]. Disponível em http://dx.doi.org/10.1590/0104-8333201400420201

PENTEADO, Cláudio; OLIVEIRA, Marilia (2019), "Autodenominação "coletivo": o que essa escolha pode nos informar", in Anais do $19^{\circ}$ Congresso Brasileiro de Sociologia, Florianópolis.

PERALVA, Angelina (2017), "O legado de 2013: Coletivos de ativistas e a agenda política brasileira", $41^{\circ}$ Encontro Anual da ANPOCS, Caxambú.

LIMA, Stephani (2018), "Coletivo", "ativista" e "horizontal": uma análise de categorias em uso no movimento social contemporâneo. Teoria e Cultura, v. 13, n. 1, pp. 18-34 [Consult. 14-08-2020]. Disponível em https://doi.org/10.34019/2318-101X.2018.v13.12382

PEREZ, Olivia C. \& FILHO, Alberto (2017). "Coletivos um balanço da literatura sobre novas formas de mobilização da sociedade civil”. Latitude, v. 11, n. 1, pp. 225-294 [Consult. 15-08-2020]. Disponível em https://www.seer.ufal.br/index.php/latitude/article/view/2812/pdf_1

PEREZ, Olivia C.; SOUZA, Bruno M. (2017), "Velhos, novos ou novíssimos movimentos sociais? As pautas e práticas dos coletivos", in Anais do $41^{\circ}$ Encontro Anual da ANPOCS; Caxambú; 2017, pp. $32 \mathrm{p}$. 
PEREZ, Olívia C. (2020), "Relações entre coletivos com as Jornadas de Junho". Opin. Publica, v. 25, n. 3, pp. 577-596 [Consult. 15-08-2020]. Disponível em https://doi.org/10.1590/180701912019253577

PEREZ, Olívia C. (2018), "Juventude universitária e política: a descrença nas instituições parlamentares e o crescimento dos coletivos", in Anais do $11^{\circ}$ Encontro da Associação Brasileira de Ciência Política, Paraná.

PEREZ, Olívia C. (2017), "Surgimento e atuação dos coletivos que discutem clivagens sociais", in Anais do III Encontro Internacional Participação, Democracia e Políticas Públicas, UFES, Vitória.

RIOS, Flavia; PEREZ, O.; RICOLDI, A. (2018), "Interseccionalidade nas mobilizações contemporâneas". Lutas Sociais, v. 22, pp. 36-51 [Consult. 08-11-2020]. Disponível em https://doi.org/10.23925/ls.v22i40.46648

SANTOS, Boventura. de S. (2013), Pela mão de Alice: o social e o político na pós-modernidade. São Paulo, Cortez.

SPINK, MJP (2011), "Pessoa, indivíduo e sujeito: notas sobre efeitos discursivos de opções conceituais", in M. J. P. Spink, P. Figueiredo, J. Brasilino (Orgs.), Psicologia social $e$ pessoalidade. Rio de Janeiro, Centro Edelstein de Pesquisas Sociais, ABRAPSO, pp. 1-22.

SAPRIEZA, Gabriela (2015), “'Nos habíamos amado tanto'. Años revueltos. Mujeres, colectivos y la pelea por el espacio público". Estudos feministas, v. 23, n. 3, pp. 939-958 [Consult. 10-07-2020]. Disponível em https://doi.org/10.1590/0104-026X2015v23n3p933.

SILVA, Wagner; CAMPOS, Deivison (2019), "Os dois lados do espelho: a cobertura midiática e as publicações do coletivo negro balanta no embate sobre as cotas na UFRGS". Revista Prâksis, v. 1, pp. 123-143 [Consult. 10-08-2020]. Disponível em https://doi.org/10.25112/rpr.v1i0.1734

SIQUEIRA, José Luiz Dias; LAGO, Angela Maria Chagas Villaluso (2012), "Coletivo da música: um estudo sobre relações entre arte e saúde mental". Estudos Interdisciplinares de Psicologia. v. 3. n. 1, pp. 93-111 [Consult. 11-09-2020]. Disponível em http://pepsic.bvsalud.org/scielo.php?script=sci_arttext\&pid=S223664072012000100007\&lng=pt\& nrm=iso

TARROW, Sidney (2009), O poder em movimento: movimentos sociais e confronto político. Petrópolis, Vozes.

TILLY, Charles (2010), "Os movimentos sociais como política". Revista Brasileira de Ciência Política, Brasília, n. 3, pp. 133-160.

TOURAINE, Alain (2006), "Na fronteira dos movimentos sociais". Sociedade e Estado, v. 21, n. 1, pp. 17-28 [Consult. 11-09-2020]. Disponível em https://www.scielo.br/j/se/a/3QY76c7QYKM6NjnjXV5y7Wk/?lang=pt

VALK, Anne M (2002), "Living a Feminist Lifestyle: The Intersection of Theory and Action in a Lesbian Feminist Collective". Feminist Studies, v. 28, n. 2, Second Wave Feminism in the United States, pp. 303-332 [Consult. 10-08-2020]. Disponível em https://doi.org/10.2307/3178744 


\begin{abstract}
This article has as its theme and object the "collectives", organizations that have been pointed out in the literature, as a "new" mobilization of people who are formed in Brazilian society. Through the studies already produced, some characteristics are attributed and among them are: fluidity, fragmentation and heterogeneity. The aim of this work is to contribute to an understanding of collectives not exclusively focused on their "organizational" analysis, but to enter more specifically in the field of identities that form these organizations through their subjects and objectives. The data analyzed comes from empirical research carried out with six collectives from six states in the Northeast Region, where all present different social markers of the difference in their constructions.
\end{abstract}

Keywords: collectives; modernity; postmodernity; identities.

\title{
Resumen
}

Este artículo tiene como tema y objeto los "colectivos", organizaciones señaladas en la literatura, como una "nueva" movilización de personas que se forman en la sociedad brasileña. A través de los estudios ya elaborados se atribuyen algunas características y entre ellas se encuentran: fluidez, fragmentación y heterogeneidad. El objetivo de este trabajo es contribuir a la comprensión de los colectivos no exclusivamente centrados en su análisis "organizacional", sino a adentrarse más específicamente en el campo de las identidades que forman estas organizaciones a través de sus sujetos y objetivos. Los datos analizados provienen de una investigación empírica realizada con seis colectivos de seis estados de la Región Nordeste, donde todos presentan diferentes marcadores sociales de la diferencia en sus construcciones.

Palabras llave: colectivos; modernidad; pos modernidad; identidades. 